\title{
Human Enhancement in the EU ${ }^{1}$
}

\author{
MIRKO GARASIC \\ Center for Ethics and Global Politics, LUISS University and Centre \\ for Human Bioethics, Monash University \\ mirko.garasic@monash.edu
}

\begin{abstract}
Many academics in the Western world favour Human Enhancement (HE) with the motto: "if we can, we should." It is hard to deny the appeal of the idea of sparing or ridding human beings of some of our "weaknesses." This idea is instinctively appealing, but once certain factors are considered, the morality of such an approach becomes less convincing. This article analyses the political dimension of $H E$, defining whether or not the European Union (EU) has a common stance on the issue. If HE is morally condemned at a theoretical level, the practical question arises of whether the EU shares a moral stance on the issue. A positive answer to this question will help reinforce a European identity, whereas a negative one will push us to question its appropriateness and will help to provide the necessary tools to change the current state of affairs.
\end{abstract}

Keywords: Bioethics, Biopolitics, European Union, Genetic Engineering, Human Enhancement, Justice.

\section{Introduction}

Human enhancement (henceforth HE) has gained increased visibility and popularity in the last decade. This is as a result of a substantial increase in the number of fields interested in the topic, namely: nanotechnology, biotechnology, information technology, and cognitive science (NBIC). ${ }^{2}$ The rapid innovation in these fields has created a theoretical space for speculation over the moral acceptability of aiming to improve or expand human capacities through the implementation of genetic engineering, drugs and technology.

Many academics in the Western world, including both scientists and philosophers, now favour the enhancement of human beings with the tools of science, and the

\footnotetext{
${ }^{1}$ This work has been funded by the European Union through the EUOSSIC Erasmus Mundus Fellowship. I am grateful to both my home (Center for Ethics and Global Politics-LUISS University) and host (Centre for Human Bioethics-Monash University) Institutions for having contributed in the shaping of this work, but I am particularly grateful to Justin Oakley, Philippa McIlroy and Euzebiusz Jamrozik for their help and support. I also want to thank several anonymous referees for the ANZJES for helpful comments on earlier versions of this paper. ${ }^{2}$ E. A. Williams, Good, Better, Best: The Human Quest for Enhancement, http://www.aaas.org/spp/sfrl/projects/human_enhancement/pdfs/HESummaryReport.pdf, accessed 22 October 2011.
} 
motto: "if we can, we should" is sometimes used to summarise this position. 3 The appeal of reducing human "weakness" and potentially improving a range of human abilities is obvious, but both moral and political questions remain as sources of dissent. $4 \mathrm{HE}$ - a term whose appropriateness has already been brought into question 5 - is predominantly discussed in the field of bioethics, but in this work, we analyse the meaning of $\mathrm{HE}$ in a more political dimension, and in so doing define whether or not the EU has a common stance on the issue.

The implementation of HE in the future policies of the EU or other nations will have a considerable political impact. It is therefore our duty to question its appropriateness at a transnational level. Determining the presence or absence of a common regional stance on the topic would certainly help to facilitate the needed international dialogue on the matter. A shared position will help reinforce a common European identity, whereas a negative one will push us to question its appropriateness and drive changes in the current state of affairs.

This article will first define HE before considering the positions of representatives of bioconservatism (Habermas) and transhumanism (Savulescu, Harris). After exploring both positions, the next step will be to analyse the current situation in the EU, with special emphasis placed on a study commissioned by the European Parliament. Adding to the critical portrayal of transhumanism highlighted by the study, arguments will be made in favour of the need for the EU to rediscover an alternative way of understanding progress especially with regards to biotechnology. The core of this alternative conceptualisation of progress is a form of Kantian autonomy that will give appropriate weight to the concepts of duty and trust. To highlight their fundamental role in relation to $\mathrm{HE}$, the final section of the paper will examine the work of Onora O’Neill.

\section{What do we mean when we talk about Human Enhancement?}

Before bringing this analysis into the European context, the first task is to clarify the notion at its centre. In order to do that we shall attempt to answer a fundamental question: what do we mean when we talk about Human Enhancement?

In recent years Nick Bostrom and Rebecca Roache have demonstrated that exponential developments in nanotechnologies, synthetic biology, neurology and genetic engineering have created the premises for a reconsideration of what it means to be human, as well as in which way(s) and to what extent we should interfere with

\footnotetext{
3 The literature in support of this claim is vast, but particularly strong claims in this direction have been made by three influential bioethicists based in the UK: Nick Bostrom, John Harris and Julian Savulescu. See, amongst others: N. Bostrom, 'Human Genetic Enhancements: A Transhumanist Perspective', Journal of Value Inquiry, Vol. 37, No. 4, 2003, pp. 493-506; J. Harris, Enhancing Evolution: The Ethical Case for Making Better People, Princeton, NJ, Princeton University Press, 2007; J. Harris, 'The Survival Lottery', Philosophy, Vol 50, No. 191, 1975, pp.81-87; J. Savulescu, 'Genetic Interventions and the Ethics of Enhancement of Human Beings,' in B. Steinbock (ed.), The Oxford Handbook on Bioethics, Oxford, Oxford University Press, 2006, pp.516-535; J. Savulescu, 'New Breeds of Humans: The Moral Obligation to Enhance,' Ethics, Law and Moral Philosophy of Reproductive Biomedicine, Vol 1, No 1, 2005, pp.36-39.

4 For sake of clarity, it should be acknowledged from the beginning that the position of this paper is critical towards HE. This work attempts to show how this approach could influence the European Union's policies and equitable access to health resources.

5 For example, in the course of an AAAS workshop, Zach Lynch proposed to use "enablement" rather than "enhancement" when referring to these cases, because this latter term is politically charged with the implication of some form of superiority in the enhancers. Williams, op.cit., p.1.
} 
humanity's "natural disposition." 6 Now not only can the most basic human capacities of an individual be restored to their initial levels before an injury, illness; these basic capabilites can also be enhanced.

A comparison between enhancement and therapy is instructive. While therapy aims to fix a problem or dysfunction and thereby allow the individual to regain a status of "normality," enhancement aims to break the barriers of normality and go beyond the "natural limits" of mankind. This controversial distinction needs to be clarified. In this paper therapeutic treatment is defined as: a) designed to re-establish a standard level of functionality; b) reversible; c) less invasive and expensive than enhancement. In contrast, enhancing treatment is: a) designed to move the level of functionality above the standard; b) not easily reversible; c) more invasive and expensive than therapy. The following example elucidates the above definitions. The availability, purchase - and use - of a pair of glasses could be justified as part of the therapeutic treatment of poor vision, whereas, the process of neural implantation aimed at increasing one's memory by $20 \%$ would not. While the overlapping threshold between therapy and enhancement is open to debate, 7 it is nonetheless important to have a frame of reference for the terms considered.

This article will be concentrated towards putting forward several case scenarios that may help the reader understand the debate in greater depth. A therapeutic intervention aims to return the individual to their normal state. For instance, arm surgery that will allow the individual in question to re-establish her initial condition as morally and legally acceptable. Those supporting HE go a few steps further, affirming that funds should be allocated and research should be aimed at supporting the creation of individuals that will go beyond their natural limits before their health is jeopardised by an accident or an illness. For example, a surgical intervention that would replace a person's fully functional arm with a new bionic one allowing them to lift 500 kilograms without breaking a sweat would be considered an enhancement.

The recent example of the South-African runner Oscar Pistorius encapsulates the current difficulties in drawing a distinction between enhancement and therapy. Born without fibulae, he had his legs amputated below the knee at a very young age and replaced with prosthetic legs. Thanks to his commitment to training and to the implementation of a pair of Flex-Foot Cheetahs, in 2005 Pistorious managed to win the T44 200m gold medal.

When his results started to match and pass those of the "normal" runners however, the debate over therapy and enhancement turned into a polemic. In 2007, the International Association of Athletic Federations (IAAF) reported that "Pistorius was able to run at the same speed as able bodied athletes while using less energy and that his prosthetic limbs gave him an advantage over able-bodied athletes."8 By common standards, when Pistorious started using prosthetic legs as a child, he had merely undergone therapeutic treatment. Yet, in a situation where his artificial limb prostheses were identified to be a technical advantage, he was considered to have

\footnotetext{
${ }^{6}$ N. Bostrom and R.Roache, 'Ethical Issues in Human Enhancement', in New Waves in Applied Ethics, J. Ryberg, T. Petersen and C. Wolf (eds.), Basingstoke, Palgrave Macmillan, 2008, pp.120-152.

7 For example Francis Fukuyama argues that governments should define more clearly what are the differences between therapy and enhancement, pushing towards the former and avoiding the latter. F. Fukuyama, Our Posthuman Future: Consequences of the Biotechnology Revolution, London, Profile Books, 2002.

8 O. Pistorius, <http://www.oscarpistorius.com>, accessed 15 May 2012.
} 
undergone enhancement. Of course, this makes his case even more germane to the ethical and political dimensions of the therapy versus enhancement debate: is it 'enhancement' if the person in question is responding to a congenital condition over which she had no control? This question, although important, is not central to the current paper and will not be addressed further. However, this example is nonetheless very useful to highlight some of the problems inherent to the therapy/enhancement distinction.

We can make a general distinction between those arguing in favour of HE (described as transhumanists) and those against interventions on the human condition that go beyond "standard" function (this latter group is that of the bioconservatives). In the following sections of the paper, we consider the work of some the main exponents of the two schools of thought.

\section{Defending Bioconservatism: Habermas vs. Eugenics}

Even though the ideology had its genesis in Great Britain and found much success in the United States, ${ }^{9}$ the field of eugenics is associated with Nazi Germany, and the atrocious consequences of their projects. It is no surprise that the terrible and recent experience of the National Socialist era makes discussion of - let alone policy about $\mathrm{HE}$ in Europe an especially difficult topic. Habermas' much criticised argument against eugenics ${ }^{10}$ has been based on the idea that the application of any form of genetic enhancement to our offspring would undermine the autonomy of those yetto-be-born individuals. Many critics have raised points against his position, but here the focus will be limited to the following four critiques.

These critiques are as follows: 1) the idealisation of autonomy cannot be given to be necessarily content-neutral; 112 ) the so-called "we've already done it (and everything's been okay)" argument; ${ }^{12} 3$ ) the limitations of physical autonomy that a severely disabled person might have to suffer as a result of a lack of implementation of accessible genetic enhancement tools will be a much greater destabilising factor on the individual's freedom to pursue her own priorities in life than the knowledge that her parents chose her genes scientifically; ${ }^{13}$ 4) Agar's argument: if we accept environmental enhancement as acceptable parental behaviour, why should we not think about genetic enhancement according to the same principles? ${ }^{14}$

The fourth critique is of particular importance for the purpose of this article. In fact, while it is easier to agree with the first three critiques of Habermas' defence of autonomy against eugenics, it is interesting to note that the Agarian stand is paradoxically useful to sustain Habermas' view. For Habermas, autonomy is the key

\footnotetext{
9 The term "eugenics" (from the Greek "well-born”) was coined by Francis Galton in 1883 and his theory gained immediate success in both Britain and the US. In the US, through the work of Charles Davenport, the movement become global and turned the theory into practice with the implementation of numerous enforced treatments that current liberal eugenicists claim to be in contrast with Galton's initial theory.

${ }^{10} \mathrm{~J}$. Habermas, The Future of Human nature: On the Way to a Liberal Eugenics?, Cambridge UK, Polity Press, 2003.

${ }^{11}$ Regarding this point there is a very interesting analysis of autonomy in Chapter 5 of J. Taylor, Practical Autonomy and Bioethics, New York, Routledge, 2009, pp.63-82.

${ }^{12}$ E. Parens, 'Should We Hold the (Germ) Line?,' Journal of Law, Medicine and Ethics, Vol. 23, No.2, 1995, pp. 173-76, p.173.

13 B.Prusak, 'Rethinking “Liberal Eugenics”: Reflections and Questions on Habermas on Bioethics,' Hastings Center Report, Vol. 35, No .6, 2005, pp.31-42.

${ }^{14}$ N. Agar, 'Liberal Eugenics' in H. Kuhse and P. Singer (eds.), Bioethics: An Anthology, Oxford, Blackwell, 1999.
} 
concept that can allow us to critique HE. However, in order for autonomy to be used successfully in this discussion, we need to consider the O'Neillian version of autonomy rather than focusing on the individualistic version put forward by Habermas that is normally referred to in bioethical contexts. O'Neill suggests a notion of principled autonomy that will be based on the idea that an autonomous act "could be adopted by all others." 15

Before turning to this, however, we must analyse Agar's argument in reverse. Given that environmental enhancement is producing an ever-growing gap between the 'haves' and the 'have-nots,' and in light of the negative moral and political results that this entails, is it not reasonable to affirm that we should not implement genetic enhancement, either?

Even if HE could be shown not to jeopardise the autonomy of our own offspring, perhaps its use would nonetheless undermine the autonomy of other human beings around the globe not in a position to access, afford or who simply are not willing to use genetic enhancement. ${ }^{16}$ It is important to remember that Habermas considers autonomy more as a social characteristic than as part of individual human beings in isolation. Mark Warren writes: "Habermas does not treat autonomy as something given to individuals by nature. [...] Rather, he conceptualizes autonomy in such a way that is one developmental possibility embedded within social relations as such."17

\section{Some Transhumanist arguments}

In their article "To Gattaca and beyond," Julian Savulescu and Bennett Foddy portray a picture of $\mathrm{HE}$ as a tool to improve social injustice: "Through genetic testing, we could tailor education and support to individual needs. It might mean everyone can have a decent chance of a decent life, regardless of the genetic lottery."18

There is little doubt that many transhumanists are moved by a genuine will to make the world better but, while admiring their noble intentions, it is hard to see how $\mathrm{HE}$ would in fact help the process of human equalisation in the way that Savulescu and Foddy hope. The reason for this scepticism is contained in an earlier part of the same article: "Should we embrace or reject a Gattaca-style world of genetic testing? Our world is not so different. [...] We are repelled in part by the world of Gattaca because it is so like ours."19

The quotation above only reinforces doubts over the moral legitimacy of HE and its appropriateness in both a global and European context. After all, why should we

\footnotetext{
${ }_{15}$ O. O'Neill, Autonomy and Trust in Bioethics, Cambridge, Cambridge University Press, 2002, p.85.

${ }_{16}$ An argument could be made on why HE should be subject to a "dictatorship of the non-adopters," but -due to lack of space- this will not be developed further here. However, a brief response to such a critique can be found in the view put forward by, amongst others, Leslie Cannold: HE is damaging in its existence because it forces everyone into a rat race that will negatively affect especially those not willing to actively participate. As a result, we might be better off rejecting HE altogether. L. Cannold, 'Reprogenetic technologies: balancing parental procreative autonomy and social equity and justice', in L. Skene and J. Thomson (eds.), The Sorting Society, Cambridge, Cambridge University Press, 2008, pp.69-84.

${ }_{17}$ M. Warren, 'The Self in Discursive Democracy', in S. K. White (ed.), The Cambridge Companion to Habermas, Cambridge, Cambridge University Press, 1995, pp. 167-200,p.172.

${ }^{18}$ J. Savulescu and B. Foddy, 'To Gattaca and Beyond,' The Age, $29^{\text {th }}$ April, 2007, <http://www.theage.com.au/news/opinion/to-gattaca-and-beyond/2007/04/28/1177460039850.html\%20>, accessed 21 October 2011. 19 Ibid.
} 
expect that its implementation would produce anything different from a Gattaca-style world?

\section{The Rise of Geneticism?}

"An enhancement (as we are using the term) is something of benefit to the individual." 20 This commonly shared transhumanist definition of enhancement constitutes sufficient proof that distributive justice is not truly a central consideration of HE ideology. After all, at the root of HE, there is a Hegelian vision of progress. An article in the Times by John Harris gives a good example of this approach to human history from a transhumanist perspective. ${ }^{21}$ Harris draws a parallel between $\mathrm{HE}$ and the use of candles, affirming that we should not ban the former in light of the benefits that we can perceive to have achieved through the use of the latter. The only things we have to work on, Harris says, are working hours, minimum wages and so on.

In response to this historical analysis (and, as a result, of the potential outcomes of future implementations of $\mathrm{HE}$ ), it might be worth applying a Left-Hegelian perspective to consider that the example proposed by Harris may demonstrate that the advent of candles may have been the point at which the level of exploitation of workers reached a tipping point. The industrial revolution has certainly resulted in certain benefits and progress for a part of humanity, but it is equally true that it represented a turning point in delineating once and for all the gap between rich and poor countries. If such a gap has been consistently increasing since its inception, are we sure that we want to start another revolution that might run along the same tracks? Most importantly, could we convincingly affirm that this process would constitute an enhancement for humanity as a whole rather than only for a select or lucky few?22

To answer these questions, the following sections analyse the accuracy of this historical version of progress within the European tradition. This will illustrate that, if the EU wants to survive its current identity crisis, it needs to reconsider what its own history really meant to say about the significance of progress.

\footnotetext{
${ }^{20}$ S. Chan and J. Harris, 'In Support of Human Enhancement,' Studies in Ethics, Law, and Technology, Vol. 1, No. 1, 2007, pp.1-3.

${ }^{21}$ J. Harris, 'Who's afraid of synthetic human?,' The Times, $17^{\text {th }}$ May, 2008,

<http://www.timesonline.co.uk/tol/comment/columnists/guest_contributors/article3949986.ece>, accessed 21 October, 2011.

${ }^{22}$ It should be clear that there is no intention to argue that, on balance, we should lament the Industrial Revolution. However, attention should be given to the negative outcomes it has produced. More specifically, we should focus on the increasing gap between rich and poor. This gap has not been increasing in a linear fashion in all contexts and all time periods since the industrial revolution but it is widely accepted that it has steadily increased nonetheless. In support of this view it is important to consider the data produced by the UN reports and the "Millenium Goals" of the organization: < http://www.un.org/esa/socdev/rwss/docs/2010/fullreport.pdf $>$ and and <http://www.un.org/millenniumgoals/> accessed 23 June 2012. More specifically relating the "costs and benefits" approach to this context however, consider: D. Callahan, 'Transforming Mortality: Technology and the Allocation of Resources,' Southern California Law Review, Vol. 65, No. 205, 1991, pp.205-224.; N. Daniels, 'Technology and resource allocation: old problems in new clothes,' Southern California Law Review, Vol. 65, No. 1, 1991, pp.225-240.
} 


\section{What is the position on Human Enhancement in Europe?}

Even if the EU and member countries do not have formal directives concerning HE, there have been many attempts to define and shape a clearer position on the issue. ${ }^{23}$ Among those, a study commissioned by the European Parliament and completed in May $2009^{24}$ was particularly successful in bringing to the light a number of important points related to the HE debate in Europe.

Interestingly, in relation to the conception of progress at the root of transhumanist positions such as that of Harris considered in the previous section, Coenen et al. write:

The transhumanist ideology with its peculiar notions of progress and a betterment of humanity is, in deviation of the mainstream of social utopianism and of modern progressivism, imbued with [...] quasi-messianic hopes. ${ }^{25}$

The authors of the study use this critique to stress the importance of understanding that the challenge of $\mathrm{HE}$ goes beyond a strict bioethical analysis of the moral permissibility of certain practices. The prioritisation of the conception of progress intrinsically valued by transhumanists could have far-reaching damaging effects on European identity, as the spread of its acceptance of HE in Europe would result in substantial changes in both solidarity and healthcare systems. In light of this, the next section of this article will analyse what the duties of the EU are towards its citizens.

\section{The duty of the EU: a new European version of progress}

It is clear that transhumanism, and more generally ablenism (the position that discriminatorily considers the capability of doing something as the judgement measure to evaluate the value of a person or not), rely on a Hegelian notion of progress that is deeply entrenched in the European cultural heritage.

However, aside from the validity of such an interpretation of the Hegelian conception (one could even view it as a distortion), it is important to point out that Kant's ideas are also of central importance among the exponents of the European Enlightenment. Kant's work provided the foundations for internationally collaborative documents such as the Universal Declaration of Human Rights, and his notion of Cosmopolitanism has been at the core of the success of the EU integration model to date. Kantian values have a clear application in the HE debate. The EU should shape its approach to $\mathrm{HE}$ in a way that is sensitive towards the members of its community not only as individual states, but, more importantly, as the single individuals which constitute such entities. This will help redirect the current debate over HE and other bioethical and biopolitical issues to its initial wrong. It will make it clear that we need to reconsider the version of autonomy that allows that the individual should function independently of context.

\footnotetext{
23The Oviedo Convention is the most relevant document concerning bioethical issues, <http://conventions.coe.int/Treaty/en/Treaties/html/164.htm>, accessed 15 May 2012.

24 'Human Enhancement,' European Parliament's Science and Technology Options Assessment (STOA) website:

<http://www.itas.kit.edu/downloads/news/news_etag_couao9a.pdf>, accessed 15 May 2012.

25 Ibid., p.112.
} 
We have to rediscover a Kantian version of autonomy defined by Onora O’Neill as a principled autonomy that does not focus on the atomistic misconception of what it means to be autonomous, but rather gives relevance to duty and trust, central aspects of Kant's theory, which are often overlooked.

\section{Duty, Trust and Autonomy}

O'Neill attempts to address the limits of our current misinterpretation of autonomy in medico-ethical contexts by stressing that there is evidence of a parallel loss of public trust in inverse correlation to the rise of the individualistic variant of this concept. Her position aims to underline the peculiarity of a situation in which an increase in concern for the rights of the individual has been accompanied by a growing "mistrust of various professions, experts and of public authorities." 26 Her argument proposes a move away from this towards a more consistent way of dealing with the notion and its applications.

Identifying patient autonomy as the ultimate yardstick by which to judge the fairness of a course of treatment (therapeutic or enhancing) is more likely to engender suspicion (as indeed it already has) ${ }^{27}$ especially when contrasted with trust as a central criterion. Clearly, empirical evidence of changes in the levels of trust in medical professionals varies greatly according to period and country and O'Neill's analysis relies on an acceptance of cited public opinion polls as valid. This validity could be disputed. Yet, her work raises important questions related to the definition of autonomy: should we choose between respect for individual autonomy and relations of trust? ${ }^{28}$ Do the concepts of autonomy and respect thereof necessarily undermine the possibility of their coexistence with trust? Is the loss of trust the only way to guarantee an increase in autonomy?29 In order to respond to these questions she draws a distinction between "individual autonomy" - which we might consider to be the mainstream understanding of autonomy - and "principled autonomy," O'Neill's own improved concept, capable of combining autonomy and trust $3^{\circ}$ rather than demanding a choice between them.

According to O'Neill, the limits of the moral validity of individual autonomy lie in the implicit acceptance of independence as the key value in an autonomous human being. Expressed thus, there would be no good reason for our independence to be limited in any way when deciding or acting, as the ultimately decisive condition would always be our own judgement, even if this might also result in the presence of disconnected individuals functioning in proximity to one another but not together. As O’Neill says:

Independent action can be important or trivial, heroic or brutal, helpful or selfish, admired or distressing to others. If we view individual autonomy as mere independence, its merits will be highly variable..$^{11}$

\footnotetext{
${ }^{26}$ O’Neill, op. cit., p. 3.

27 D. Callahan, 'When Self-determination Runs Amok', The Hastings Center Report, Vol. 22, No.2, 1992, pp.52-

55 .

${ }_{28}$ O’Neill, op. cit., p.4.

29 Ibid., p.16.

3о Ibid., p.17: "Autonomy and trust are [...] compatible, and even mutually supporting."

${ }^{31}$ Ibid., p.25.
} 
Gerald Dworkin's response to this is instructive. He notes that O'Neill's affirmation seems at first to be impervious, but we should bear in mind that is important to give relevance to the fact that such a "despicable" version of autonomy still manages to be consistent with other values such as loyalty or love. $3^{2}$ These qualities require an intrinsically positive attitude towards the interaction with other individuals resulting in a somewhat less ruthless version of autonomy than that described by O'Neill.

Having explained the notion of individual autonomy, O'Neill moves on to address her main concern in the contemporary mainstream understanding of autonomy: how does the increase of individual autonomy necessarily result in a decrease of trust? As mentioned above, and as pointed out by Alan Thomas,33 O’Neill highlights a paradox in our society and, more specifically, in the field of biomedical ethics: despite an undeniable increase in patients' autonomy within the patient-doctor relationship, the overall trust in healthcare authorities has decreased drastically in recent years. ${ }^{34}$ On the one hand, we as patients have increased our power to enforce our autonomous decisions; on the other hand we have less trust than before in the doctors who are charged with putting our decisions in to practice. A possible explanation for this apparent contradiction can be found in the acknowledgement that the rise of individual autonomy in decision-making has affected almost every facet of society. Thus this change particularly affects doctors involved in sensitive issues such as abortion or withdrawal of treatment, producing cases where the will of the patient to be treated (or not) might clash with the will of the doctor to treat (or not).

A possible solution to this would be, as some feminist positions argue, 35 a reevaluation of other values within the definition of autonomy. Rationality might well be central to autonomy but it is not the only value to consider when establishing whether an individual can be deemed autonomous or not. O'Neill aims to make this recognition the starting point for a reanalysis of the current state of the patientdoctor relationship, and also more broadly of Kant's definition of autonomy. Her conception of autonomy sees the principled autonomous agent obliged to make her choices within a predefined moral set of normative values. This is one way of overcoming the paternalism-autonomy dualism and allowing for an internal regulative system within the concept of autonomy. In other words, we allow an intrinsic form of paternalism in principled autonomy, thus overcoming the classical conflict between the two notions.

The conflict between an external or an internal assessment of what is permissible or not clearly represents a problematic issue in bioethical contexts as well as in more 'purely political' ones. In order to synthesise the two levels of the argument, the next section of the paper will provide a more psychological reading of autonomy that illustrates the fundamental change that needs to occur in bioethics as well as in

\footnotetext{
$3^{2}$ G. Dworkin, 'Can you trust autonomy?', The Hastings Center Report, Vol. 33, No. 2, 2003, pp.42-44.

33 A. Thomas, 'Autonomy and Trust in Bioethics: a review,' Notre Dame Philosophical Reviews, Kent University, 2004, <http://ndpr.nd.edu/>, accessed 19 December, 2011: “O’Neill's central concern is the paradox that recent bioethics has seen an increase in the safeguarding of individual autonomy and yet increasing public mistrust of the professionals and institutions centrally concerned with bioethical issues."

34 Clearly, controversial cases like the ones presented in this thesis can hardly work in favour of reducing distrust of authorities.

35 See, amongst others: G. Clement, Care, Autonomy, and Justice: Feminism and the Ethic of Care, Westview Press, 1996; S. Saharso, 'Feminist Ethics, Autonomy and the Politics of Multiculturalism,' Feminist Theory, Vol. 4, No. 2, Aug 2002, pp.199-215, C. Mackenzie and N. Stoljar (eds.), Relational Autonomy: Feminist Perspectives on Autonomy, Agency, and the Social Self, Oxford, Oxford University Press, 2000.
} 
politics. However, there are alternative ways of dealing with autonomy that will be considered first.

Robert Zaner's work complements O'Neill's idea of trust as a crucial social asset that might merit a more central role through its integration with autonomy:

The dialogical partners who are able to sustain moral dialogue, thus, effectively collaborate in each other's freedom, as Gabriel Marcel long ago emphasized. $3^{6}$...Freedom is not an act of solitary consciousness or pure will; it is rather the mutually enabling act which occurs, when and if it does occur, at the heart of moral dialogue. 37

We must understand that a standalone autonomous being is a practical impossibility in the vast majority of cases around the globe (with some exceptions, for example hermits).

Kant was aware of the social dimension of autonomy, and for this very reason he stressed the importance of refraining from following directives from heteronomous inputs. Yet, he also stresses duty as a fundamental feature of autonomy. This refers to duty towards oneself, but also duties towards the universe, which obviously includes, in more specific and proximate terms, the members of society around us. ${ }^{8}$ In acknowledging this truth, we must not fear a return to an era of imposition by the family, community or state over the single human being, but rather, we should take this opportunity to understand in greater depth the fact that it is human nature to be relatively autonomous and independent from those around us.

Clearly, to people born and raised in a liberal context that exalts the absence of governance by others (whether active or passive), this may at first sound repressive but, as O'Neill rightly points out, other fields of applied ethics, in particular environmental ethics, have already shown that the way out of our otherwise doomed future is to embrace a different perspective on the one global issue (i.e. preserving Earth's ecosystem) that could focus our commonality of intent. Bioethics is no different since, as this paper has shown, the supposed objectivity and detachment from a contingent political agenda is fictional.

Once we realise that our right to exercise our freedom depends upon the $a$ priori connection with the "outside world," it becomes absurd to deny the necessity of interaction with others as an affirmation of one's autonomy. However, the switch proposed is less drastic than it might first appear. It is not a matter of fully reshaping our system of interaction with others; this system remains in place. It is our modes of including others in the decision processes that lead individuals to make certain choices that need to change.

\footnotetext{
${ }^{36}$ As quoted in: G. Marcel, Le mystère de l'être, I, Aubier, Paris, Editions Montaigne, 1951, p.144.

37 R. M. Zaner, 'Failed or Ongoing Dialogues?,' in L. D. Kliever (ed.), Dax's Case-Essays in Medical Ethics and Human Meaning, Southern Methodist University Press, 1989, p.57.

${ }^{38}$ It might be worth considering Kant's "political layers" of autonomy in Perpetual Peace, with the intention of applying this idea to the level of a single human being. "The state of peace among men living side by side is not the natural state (status naturalis); the natural state is one of war. This does not always mean open hostilities, but at least an unceasing threat of war. A state of peace, therefore, must be established, for in order to be secured against hostility it is not sufficient that hostilities simply be not committed; and, unless this security is pledged to each by his neighbor (a thing that can occur only in a civil state), each may treat his neighbor, from whom he demands this security, as an enemy."I. Kant., Perpetual Peace, Section II,

<http://www.mtholyoke.edu/acad/intrel/kant/kant1.htm\#fn>, accessed 19 March 2011.
} 
The EU has the possibility of shaping its identity in line with its own history and adopting principled autonomy as a guide to political decisions, including the choice about whether to adopt policies in favour of HE. A clear stand against an ideology that exalts the individual as a single unity may also represent an important turning point in the prioritisation scheme used by the political system in relation to broader issues.

\section{Conclusion}

This work has considered both transhumanists and bioconservative arguments concerning $\mathrm{HE}$, and its contextualisation in Europe. In conclusion, it appears impossible to affirm that the EU has a common stance on issues concerning HE. This is due to the multiplicity of points of view that Europe at large seems to foster in different regions of its continent and beyond its borders. Yet, there is room for redirecting Europe towards a way of conceptualising progress that is less centred on isolated individuals. As in many other issues, this should be seen not as an obstacle but rather an opportunity for Europe to shape a common identity.

This article has demonstrated that a reconsideration of Kant's notion of autonomy through the application of duty and trust in a principled form of autonomy could help the decision makers in Europe understand that some of the characteristics shared by EU Member States, such as solidarity and socialised health services, might be jeopardised by the same logic used by promoters of $\mathrm{HE}$.

The debate on HE represents an ideal opportunity to reinvigorate European cultural heritage in the modern context of bioethics. The result should help us understand the flaws inherent to the current prevailing version of autonomy and produce the necessary corrections to ensure a fairer life for European and global citizens. 